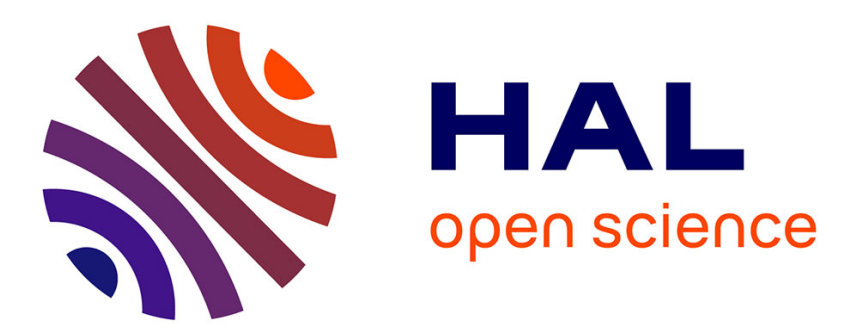

\title{
Experiment-based prototyping to design and assess cotton management systems in West Africa
}

Bruno Rapidel, Bouba S. Traoré, Fagaye Sissoko, Jacques Lançon, Jacques Wery

\section{- To cite this version:}

Bruno Rapidel, Bouba S. Traoré, Fagaye Sissoko, Jacques Lançon, Jacques Wery. Experiment-based prototyping to design and assess cotton management systems in West Africa. Agronomy for Sustainable Development, 2009, 29 (4), pp.545-556. 10.1051/agro/2009016 . hal-00886453

\section{HAL Id: hal-00886453 https://hal.science/hal-00886453}

Submitted on 1 Jan 2009

HAL is a multi-disciplinary open access archive for the deposit and dissemination of scientific research documents, whether they are published or not. The documents may come from teaching and research institutions in France or abroad, or from public or private research centers.
L'archive ouverte pluridisciplinaire HAL, est destinée au dépôt et à la diffusion de documents scientifiques de niveau recherche, publiés ou non, émanant des établissements d'enseignement et de recherche français ou étrangers, des laboratoires publics ou privés.

$$
\text { Copyright }
$$




\title{
Experiment-based prototyping to design and assess cotton management systems in West Africa
}

\author{
Bruno RAPIDEL ${ }^{1 *}$, Bouba S. TrAORÉ ${ }^{2},{\text { Fagaye } \text { SISSOKO }^{2}, \text { Jacques LANÇON }^{3} \text {, Jacques WerY }}^{4}$ \\ ${ }^{1}$ CIRAD, UMR SYSTEM CIRAD/INRA/SupAgro, 2 place Viala, 34060 Montpellier, France \\ ${ }^{2}$ Institut d'Économie Rurale, BP 258, Bamako, Mali \\ ${ }^{3}$ CIRAD, UPR Systèmes de Cultures annuels, avenue Agropolis, BP 5035, 34032 Montpellier Cedex, France \\ ${ }^{4}$ SupAgro, UMR SYSTEM CIRAD/INRA/SupAgro, 2 place Viala, 34060 Montpellier, France
}

(Accepted 7 May 2009)

\begin{abstract}
Designing innovative combinations of techniques to improve the sustainability of cropping systems in poor countries is a major challenge. Here, we developed a prototyping methodology to design, assess and adapt a crop management system for a specific set of constraints. It was applied in Mali with the aim of designing innovative prototypes of cotton management systems to be further tested and adapted by farmers. The prototype aimed at shortening the cotton cycle to overlap the rainy season. The prototype is particularly suited for late sowing and for regions where rainfall is often insufficient. We propose a conceptual model that organizes technical interventions to shorten the cotton cycle. We developed a set of indicators to evaluate the relevance of each modified technical intervention, by comparison with current farmer practices. We evaluated the overall performances of the prototype by taking into account economic, environmental and social factors. The prototype was tested and adjusted in six trials between 2002 and 2004. Our results show that the cotton growth cycle was reduced by 15 days on average, mainly through the shortening of the flowering period. The combination of much higher stand density than currently applied in the region and application of the growth regulator mepiquat chloride produced a much higher number of bolls per hectare of $+69 \%$. The prototype produced higher seed-cotton yields, of $+44 \%$ on average, and much higher gross margin than the standard cotton management system. The method was therefore successful in designing a new cotton management system that helps farmers to adapt to diverse cropping conditions.
\end{abstract}

cotton cropping system design sustainability Mali

\section{INTRODUCTION}

The cotton sector in Mali has undergone significant changes over the past 15 years - since the 1993 local currency devaluation, the cotton area has almost tripled in size and the number of cotton growers doubled. Privatization of the sector is under way. The ecological and socioeconomic conditions under which the crop is grown have changed, i.e. new areas (some of them less fertile), new farmers and new organizations. At the same time, cotton yields have decreased by $25 \%$ in the last 10 years (Devèze and Halley des Fontaines, 2005; IER/CMDT/OHVN, 1998). In 2004, cotton prices fell abruptly on the international market. These modifications in the cotton production settings should induce modifications in crop management systems.

Cotton growing has long been promoted in Mali with relatively uniform crop management systems (CMDT, 2001), which have not markedly changed over the last 10 years

\footnotetext{
*Corresponding author: bruno.rapidel@cirad.fr
}

(Traoré et al., 2006). Uniform crop management systems no longer seem suited to the diversity of cropping conditions (Fok et al., 1999) and may be partly responsible for the decreased yields. Farmers are asking for a wider range of cropping techniques, better adapted to current constraints, and cotton research is being requested to develop innovative cropping strategies (Deguine et al., 2008). The research community is thus trying to extend the range of cropping techniques for cotton in Mali. Among the methods available for designing new cropping systems, the prototyping approach of farming systems (Sterk et al., 2007; Vereijken, 1997) was chosen.

In a previous article, we presented the adaptation of this approach to Cotton Management Systems (CMS) (Lançon et al., 2007). The adapted approach consists of four steps:

- Step 1. Identification of sets of constraints, and selection of criteria for cotton management system assessment;

- Step 2. Elaboration of the theoretical prototype and definition of assessment indicators, used for the overall evaluation of the prototype; 
- Step 3. In-station experimentation, adjustment of the experimental prototype and preliminary assessment;

- Step 4. On-farm experimentation, assessment and adaptation of the prototype to reconcile farmers' goals and constraints.

In the previous article, we focused on steps 1,2 , and an initial assessment corresponding to step 3 . The selected set of constraints was "late-planted cotton with low input availability in West Africa" (step 1). A new cropping system was designed, on paper, during a workshop that brought together scientists and engineers of the cotton development institutions of West Africa. The modifications of the standard cotton management system included new genotypes, increased plant stands, and lower fertilizer and growth regulator applications. Fourteen indicators were selected to assess the economic, environmental and social performances of the prototype (step 2). The prototype was then tested in three African countries, Benin, Cameroon and Mali, in 2002 and 2003 in an initial assessment corresponding with step 3 .

The third step of the approach introduces the need to adjust the prototype, i.e. to modify it from the on-paper proposal, to allow its actual implementation in the field, and to take into account the results of its agronomic evaluation. This agronomic evaluation has to confront the theoretical objectives of the modifications introduced from the standard cotton management system with the actual results of these modifications in the field. The modifications were numerous, and a systematic evaluation of their pertinence is therefore needed. For this purpose, we consider that new indicators are needed - adjustment indicators -, so that, although the prototype is implemented as a whole, each modification can be evaluated, and eventually accepted, rejected or adapted during the adjustment process.

This article presents the on-station experimentation of this new cotton management system prototype during a 3-year instation experimentation phase (2002-2004) in the cotton production region of Mali. It focuses on its progressive adjustment using indicators derived for this purpose. Then, we present the comparison of the overall performances of the prototype with the control; we propose ways to go forward in the process of adoption of this prototype by the Malian cotton growers, and discuss some issues which may hinder this process. We conclude on the advantages and drawbacks of the approach as we implemented it in this case study.

\section{MATERIALS AND METHODS}

\subsection{Conceptual framework of the approach}

The set of constraints selected in the first step of the approach for West Africa (Lançon et al., 2007) was considered relevant for Mali during a local workshop held in Bamako in 2002 with scientists, advisors and farmers, i.e. a short growing season leading to water stress but availability of fertilizers, pesticides and labor. This short season could be due to the environment, e.g. cropping cotton in regions where rains are low and erratic, or to socioeconomic constraints on the farm, leading to late sowing, e.g. when the farmer does not own the plowing equipment and must wait for richer farmers to lend him the equipment after they have sown their own fields. In this paper, we focus on late sowing experiments.

The set of criteria and indicators for assessment of the prototype was taken from the regional workshop (Lançon et al., 2007). The list was shortened (Tab. I), and some indicators were adapted in the way they were measured or calculated, but the principle of overall performance assessment on the three pillars of sustainability was maintained.

The $\mathrm{N}$ balance is considered in its excess, as an element to estimate aquifer pollution, although it is currently mostly considered in Mali as a yield-limiting factor. In the Malian setting, almost all studies on $\mathrm{N}$ in cropping systems have reported negative budgets (van der Pol, 1992). Cotton protection against pests is necessary and, although very few studies have been published, it may have consequences on aquifer pollution (Issa, 2004).

The theoretical prototype was produced on paper in a scientific workshop held in Montpellier in 2001. It aimed at shortening the cotton cropping cycle so as to be more compatible with the short rainy season. The prototype design rationale is presented in Figure 1. It uses the conceptual model developed for cotton in Mali by Rapidel et al. (2006) whereby the cotton field is considered as a combination of a biophysical subsystem and a technical subsystem. The biophysical subsystem represents here the desired functioning of the crop, adapted to the selected set of constraints acting as the environment of this system (not represented in Fig. 1). The technical subsystem (i.e. the crop management systems to design) is a complex combination of individual techniques deduced from relationships between state or flow variables of the biophysical subsystem and individual techniques to act on them. The objective of the prototype, i.e. shortening the cotton cropping cycle, concerns the different growth phases of the cotton cropping cycle and suitable techniques are selected to reduce each phase. Three additional modifications are proposed, not to shorten the cycle but rather to adapt the functioning of the biophysical system to the shorter duration of the cycle. These modifications good boll protection, reduced fertilizer applications and weed management - are based on the hypotheses that cotton fruiting would be earlier and shorter; biomass would be lower and canopy closure quicker in the prototype. These modifications could increase profitability, without threatening the natural resource.

The theoretical prototype initially proposed for West Africa by Lançon et al. (2007) was modified for application in Mali during the local workshop already mentioned. The modifications focused on adaptation of both the control and prototype CMS, in order to take into account the local practices of cotton growers (Tab. II). The control was designed in compliance with guidelines set down by the Compagnie Malienne de Développement des Textiles (CMDT). The varieties used were NTA 93-15, an early variety bred locally for the prototype, and NTA88-6, the most commonly used variety in Mali for the control. The theoretical stand density in the prototype was 16.6 plants. $\mathrm{m}^{-2}$, i.e. $0.6 \mathrm{~m}$ between rows, $0.1 \mathrm{~m}$ between hills in the row, 1 plant per hill, while the density was 
Table I. Indicators used to assess the cotton management systems.

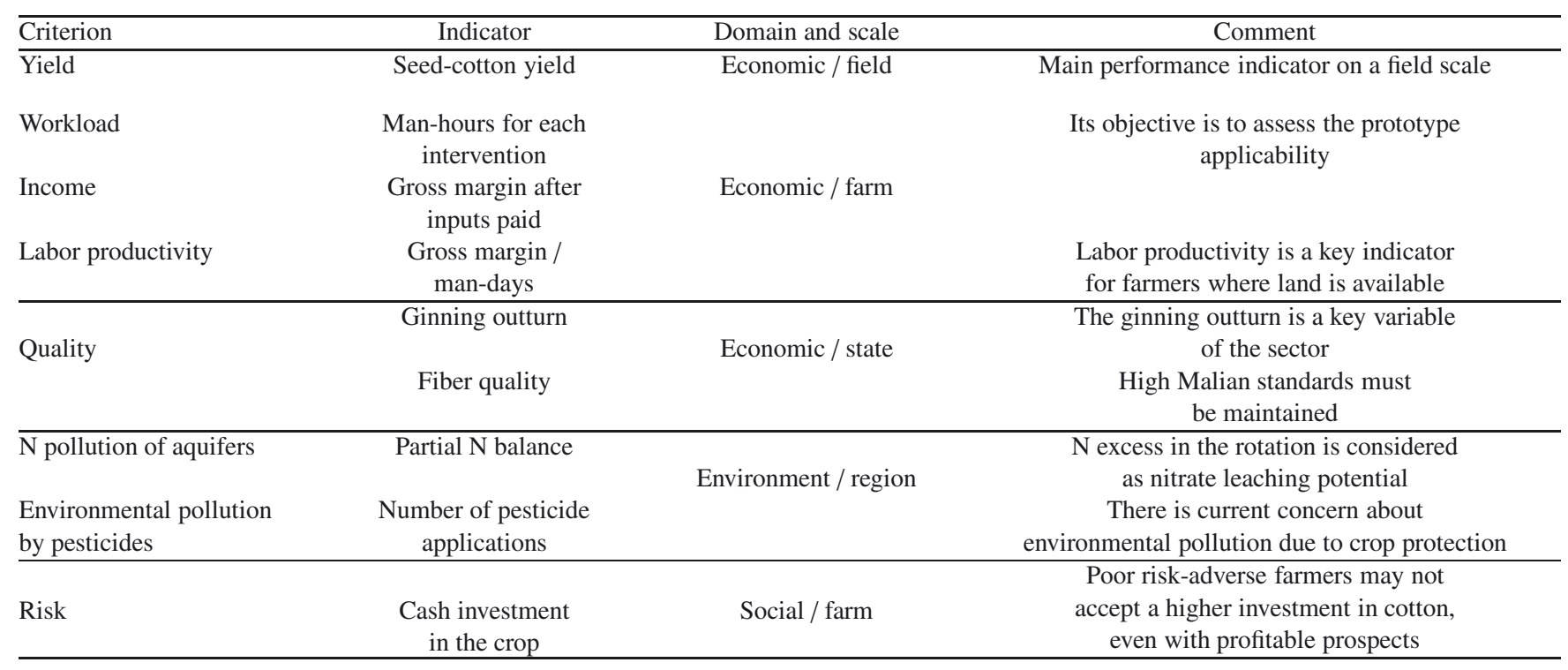

8.3 plants. $\mathrm{m}^{-2}$ in the control $0.8 \mathrm{~m}-0.3 \mathrm{~m}-2 \mathrm{p}$. Higher planting density is thought to produce earlier boll set (Buxton et al., 1979; Jones and Wells, 1997). A pre-emergence herbicide was applied in both treatments, and not only in the prototype treatment, as proposed in the regional phase, because it is currently applied in Mali when cash is available for such applications. Mepiquat chloride was applied at a low rate $\left(600 \mathrm{~mL} . \mathrm{ha}^{-1}\right)$ because high biomass production was not expected in the target growing situations. Bolls were protected against pests, mainly Helicoverpa armigera, by complying with the standard recommendations of 5-6 treatments, i.e. one every two weeks after day 45. Recommended products were also applied, using an organochloride, endosulfan, in the first two treatments to break the incipient resistance of bollworm to pyrethroids, and a mix of pyrethroids and organophosphorus compounds in the last three to four treatments.

The cotton crop was installed in all plots after a sorghum crop, the preceding year. This rotation is common among Malian farmers, sorghum benefiting from the back effect of the fertilization applied on cotton. Usually, farmers do not apply fertilizers on sorghum.

A set of adjustment indicators has been proposed to test the effect of each technical intervention taken separately on the biophysical subsystem (Fig. 1). However, in some cases, the effects of different technical interventions on the biophysical subsystem, and therefore on adjustment indicators, may be interconnected and difficult to assess separately. This may be particularly the case for the two interventions that shorten the fruiting phase, high plant density and mepiquat chloride application. The indicators selected may actually assess the overall effect of these two interventions.

This set of indicators is defined and used by researchers designing and adapting the prototype. These indicators were adapted during the experimental phase, particularly when they were not useful, not well targeted to the intervention they assess, or too difficult to estimate accurately.

\subsection{Experimental design}

The experiments were carried out between 2002 and 2004 at three experimental stations representative of the main cotton area in Mali: N'Tarla (Lat. N 12 $35^{\prime}$, Long.W $5^{\circ} 42^{\prime}$ ), Farako $\left(11^{\circ} 13^{\prime}, 5^{\circ} 27^{\prime}\right)$ and Kébila $\left(11^{\circ} 19^{\prime}, 7^{\circ} 5^{\prime}\right)$. A total of 6 experiments was implemented, to test the prototype, in Farako in 2002, 2003 and 2004, in Kébila in 2003 and 2004 and in N'Tarla only in 2003. The design of all experiments was identical: only two crop management systems were compared at each site, the prototype against the control. Prototype and control were compared in a complete Fisher block design with four replicates. Each elementary plot was $9.6 \mathrm{~m}$ wide and $20 \mathrm{~m}$ long $\left(192 \mathrm{~m}^{2}\right)$.

The trials were sown around the 10th of July. Ferruginous tropical type soils prevailed, with a predominance of sandy loam. Rainfall was recorded in each trial. The soil and rainfall conditions in the six experiments are shown in Table III.

\subsection{Measurements}

The measured variables were selected to allow for calculation of the adjustment or assessment indicators. In each plot, border areas consisted of two rows and $1 \mathrm{~m}$ on each side of them, and the measurements were made in the central area. For each experiment, the cropping interventions were recorded: soil tillage, sowing date, herbicide applications, weeding operations, mineral fertilization, insecticide applications - dates, products and doses - and date of first harvest. 


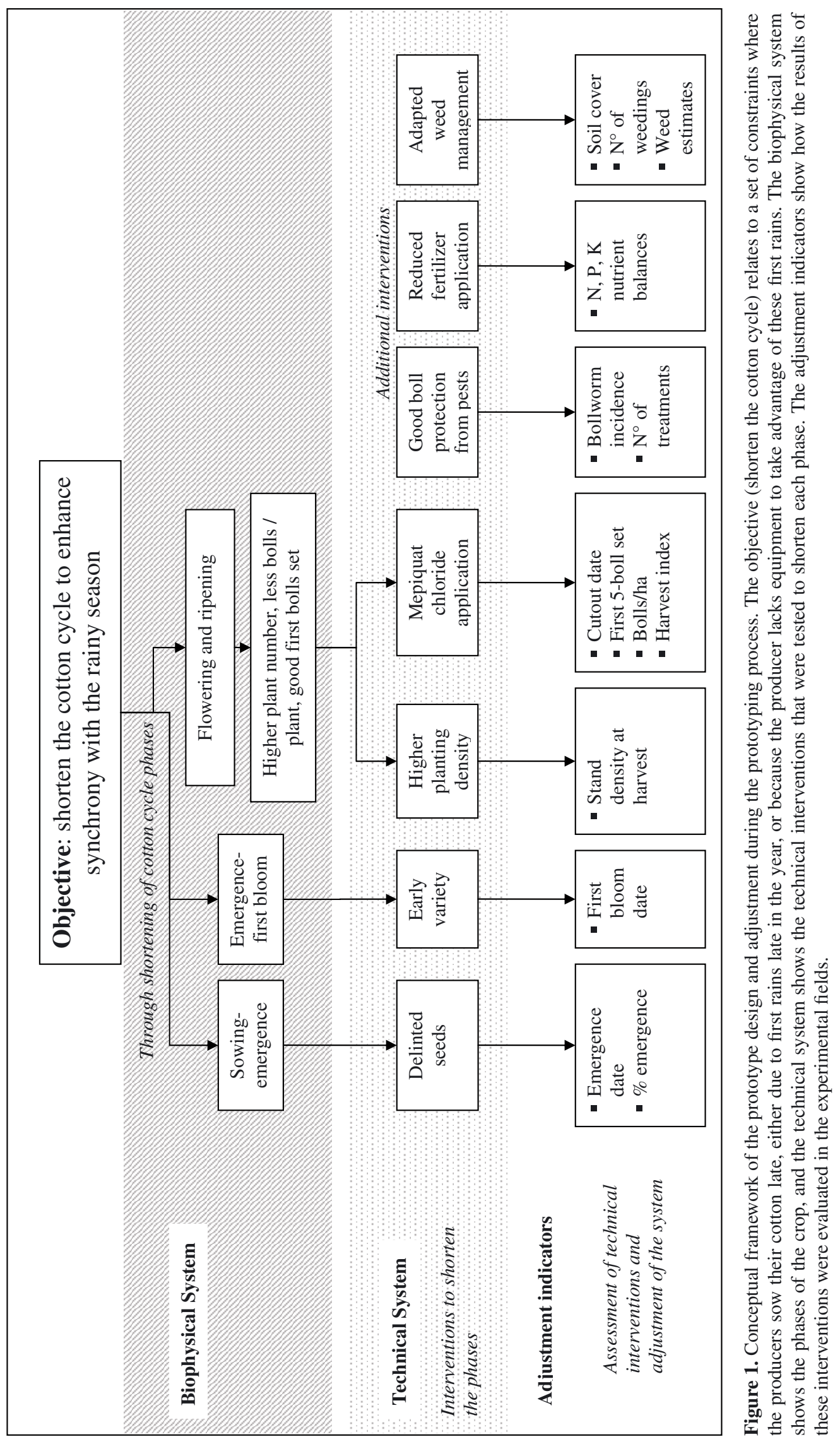


Table II. Comparison of the cropping techniques recommended by CMDT, the theoretical prototype and the experimental prototype, which was actually tested in the field (adapted from Lançon et al., 2007).

\begin{tabular}{|c|c|c|c|c|}
\hline \multicolumn{2}{|c|}{ Technical interventions } & \multirow{2}{*}{$\begin{array}{c}\text { Control } \\
\text { Plowing }\end{array}$} & \multirow{2}{*}{$\begin{array}{c}\text { Theoretical prototype } \\
\text { Plowing }\end{array}$} & \multirow{2}{*}{$\frac{\text { Experimental prototype }}{\text { Plowing }}$} \\
\hline Land preparation & Tillage & & & \\
\hline \multirow{3}{*}{ Seed } & Preparation & Fuzzy & Acid delinted & Acid delinted \\
\hline & Variety & NTA $88-6$ & Short cycle & NTA 93-15 \\
\hline & Treatment & Powder dressing & Powder dressing & Powder dressing \\
\hline \multirow{2}{*}{ Stand density } & Spacing between rows $(\mathrm{m})$ & 0.8 & 0.6 & 0.6 \\
\hline & Hills per $\mathrm{m}^{2}$ & 4.1 & 16.7 & 13 \\
\hline \multirow{3}{*}{ Fertilization } & $\mathrm{N}\left(\mathrm{kg} \cdot \mathrm{ha}^{-1}\right)$ & 38 & 22 & 31 \\
\hline & $\mathrm{P}\left(\mathrm{kg} \cdot \mathrm{ha}^{-1}\right)$ & 13 & 4 & 12 \\
\hline & $\mathrm{K}\left(\mathrm{kg} \cdot \mathrm{ha}^{-1}\right)$ & 19 & 7 & 17 \\
\hline \multirow{3}{*}{ Crop protection } & Insect control & 6 applications, 1 every & Threshold-based & 6 applications, 1 every \\
\hline & & 2 weeks after 45 DAE & decision rule & 2 weeks after 45 DAE \\
\hline & Weed control & 2 hand weedings & Threshold-based decision rule & 2 hand weedings \\
\hline Growth control & Growth regulator & None & $\begin{array}{c}\text { 2-3 Pix applications, } \\
0.6 \text { to } 11 . \mathrm{ha}^{-1}\end{array}$ & $\begin{array}{c}2 \text { Pix applications, } \\
0.4-0.6 \mathrm{~mL}^{-h^{-1}}\end{array}$ \\
\hline
\end{tabular}

Table III. Characteristics of the abiotic environment in the experimental stations.

\begin{tabular}{|c|c|c|c|c|c|c|}
\hline Experimental site & N'Tarla & & Farako & & & \\
\hline Precipitations & 2003 & 2002 & 2003 & 2004 & 2003 & 2004 \\
\hline Length of the rainy season after sowing (days) & 75 & 88 & 77 & 70 & 78 & 74 \\
\hline Rainfall after sowing $(\mathrm{mm})$ & 609 & 504 & 737 & 610 & 646 & 673 \\
\hline Soil organic matter $(\%)$ & $0.40(0.04)$ & & $0.43(0.05)$ & & & \\
\hline Total N $(\% o)$ & $0.18(0.03)$ & & $0.25(0.03)$ & & & \\
\hline P Olsen-Dabin (mg/kg) & $14.8(1.5)$ & & $8.0(7.4)$ & & & \\
\hline
\end{tabular}

* The samples were from the upper $20 \mathrm{~cm}$ soil layer and were extracted before the onset of the rainy season in 2002 and 2003 (four composite samples / year / station, standard errors are indicated between brackets).

\subsubsection{Adjustment Indicators (Fig. 1)}

The emergence date was determined in each field by counting the number of emerged plants every 2 days. The emergence date was computed as the date after which more than $50 \%$ of the hills had at least one emerged plant. The percentage of emergence was the percentage of hills with an emerged plant 4 days after the emergence date. The stand density at harvest was measured on three rows in each plot.

The first bloom date was measured by counting, every 2 days, the number of white and light pink flowers present on 10 contiguous plants in two rows, and recording the date when the cumulated value reached 20 (i.e. one flower per plant on average). The number of nodes above white flower (NAWF) was recorded at 50,60, 70, 80 and 90 days after emergence (DAE) in two rows, while selecting the first 10 plants with a white flower at the first position of the fruiting branch. The cutout date was computed as the date when NAWF reached 5 (Bourland et al., 2001). The first five bolls set was counted at harvest, at the first position of the first five fruiting branches on the main stem of the plant. Bolls per hectare were counted at harvest in three rows.
$H$. armigera incidence was determined in 10 contiguous plants in two rows by careful examination of each leaf and boll of each plant and counting the number of worms present at any growth stage. Counts were done just before each insecticide application. Weed cover was recorded weekly in each plot on five occasions beginning at 10 DAE using a scale based on the percentage of soil area covered by weeds that was developed for tropical conditions (Marnotte, 1984). The soil covered by the crop was estimated by simply measuring the average interrow width not covered by the cotton canopy at 30, 45, 60 and 70 DAE. Assuming the cotton row is continuous, its canopy is opaque and its borders are linear, this measurement represents the gap fraction of the crop.

The leaf area index (LAI) was estimated by non-destructive measurements in each plot at 30 DAE. Plant height, section of the stem above the cotyledon scar $\left(\mathrm{cm}^{2}\right)$ and number of leaves on the plant were measured in each plot on 10 contiguous tagged plants in a central row. Simultaneously, three plants outside the central area were collected. The same morphological data were recorded and the leaf dry weight and the specific leaf area were measured in the laboratory. A linear relationship was then established between plant leaf area and the 
morphological data, pooling data from all plots in a treatment. The regression equations thus obtained were then applied to the 10 plants recorded in each plot in order to determine their leaf area. Leaf area index was then calculated by inclusion of the stand density at harvest.

The nutrient balance was estimated by comparing, on the one hand, export volumes of seed cotton (and sorghum grain when applicable; as sorghum yields in the preceding years were not measured, for this balance we considered the mean yield of $704 \mathrm{~kg} \mathrm{ha}^{-1}$ from the CMDT survey in the cotton growing region) and, on the other hand, mineral fertilizer inputs, considered $100 \%$ efficient. Nutrient contents of seed cotton and sorghum grain were taken from Braud (1987).

\subsubsection{Assessment Indicators}

Yields were measured from the whole central area of the plot by weighing hand-harvested cotton seeds in the field. Above-ground biomass at harvest was measured in 10 contiguous plants in two rows. The harvest index was computed as the ratio between the seed-cotton yield and total above-ground biomass. Ginning outturn was estimated on a sample of seed cotton harvested from each plot. Fiber quality was estimated in 2002 only, by sending samples to the CIRAD laboratory in Montpellier for quality analysis.

The work load was estimated in the experimental plots by recording the time spent by working men for each technical intervention. As this indicator was only used to compare the two treatments, it was considered as valid despite the marked difference between station and farm conditions. To assess the actual effects on workload in farms, the calculated relative coefficients (e.g. $+35 \%$ work time needed for weeding the prototype compared with the control) were then applied to the standard estimates of CMDT (SSE/CMDT, 2002) in real cotton growing conditions. Gross margin after inputs paid was estimated as the difference between products (cotton price paid to farmers at the field gate) and input costs (taking the credit cost into account when applicable). Input costs have not changed significantly in recent years, and the 2006 prices were considered.

\section{RESULTS AND DISCUSSION}

\subsection{Adjustment of the prototype}

The set of indicators defined in Figure 1 was used to evaluate each intervention and to subsequently adjust the prototype. The results of this process are presented in Table IV.

Seed delinting did not modify the emergence date ( 4.5 days after sowing on average) or the percentage of emergence. The experiments were hand-sowed. Various seeds are usually put together in each hill, so the emerging plants together lift the soil crust. It is probable that, when sowing at higher density, the workers have lessened the number of seeds per hill, thus possibly offsetting the effect of delinting on emergence. As the higher stand density is a central element of the prototype, and the effects of seed delinting on cotton emergence are well documented, - see, for example, Yehouessi (1984) in Africa -, and widely used in the US (Ranney and Cauquil, 1968), seed delinting was maintained.

As shown in Table III, shortening of the period between emergence and first bloom was not effective. NTa 93-15, a local early variety selected in 2002, was changed to a US determinate variety, DES 119. First bloom was on average 1 day earlier, but the differences were not significant $(P=0.06)$.

Cutout was hastened in the prototype, indicating an earlier end of the boll-setting period. As the rate of fruiting site appearance along one axis is very stable, cotton plants of the prototype, with hastened cutout, may produce fewer fruiting sites than those in the control. Mepiquat chloride application may also reduce shedding of the first bolls set, but the corresponding increase in the first five bolls set was not always significant (Tab. IV). To summarize this shortening of the actual fruiting period better, another indicator was calculated, i.e. the percentage of total seed cotton production derived from the first five fruiting sites of the plant. This indicator was significantly modified in the prototype as compared with the control, $82 \%$ versus $68 \%$.

Boll number was higher for the prototype, but it was not linked to higher biomass production, as shown in Figure 2. In the prototype, higher stand densities and mepiquat chloride application had opposite effects on biomass production and the final effect was not consistent across experiments. Conversely, the harvest index was consistently increased in the prototype compared with the control, as shown on the right side of Figure 2. This higher harvest index suggests that an increase in $\mathrm{C}$ allocation to the bolls was achieved in the prototype.

Pest management was initially set to be identical in both treatments. As the fruiting duration was shortened in the prototype, we preferred to concentrate the same number of treatments within a shorter period (every 10 days instead of every 14 days in the control). Bolls were well protected in both cases, as very few bollworms were detected (Tab. IV). Bollworm counting is cumbersome and probably not very accurate; younger worms may or may not be detected. Thus, the indicator was modified to a simpler one for the last year of the experiment, i.e. the $\%$ of healthy bolls, which takes bolls partially perforated by worms into account. No difference was found between treatments.

Fertilizer application was initially reduced, because we expected low seed-cotton yields due to late planting, and thus low nutrient exports. The achieved yields were greater than expected and higher fertilizer rates were required to maintain a positive $\mathrm{N}$ budget. The nutrient budgets, including $\mathrm{N}$, were then positive, even when an unfertilized sorghum was included in the rotation, a common practice in Mali, and was taken into account in the budget (data not shown). Nevertheless, in this partial budget, no nutrient leaching was considered, the crop residues were assumed to be completely left in the field and the fertilizer efficiency was supposed to be total. Actual nutrient budgets may be lower when leaching, erosion and partial removal of crop residues are taken into account.

A quicker canopy cover was assumed to help the cotton crop in its competition against weeds. The initially chosen indicator for canopy cover, row width covered by the canopy, 


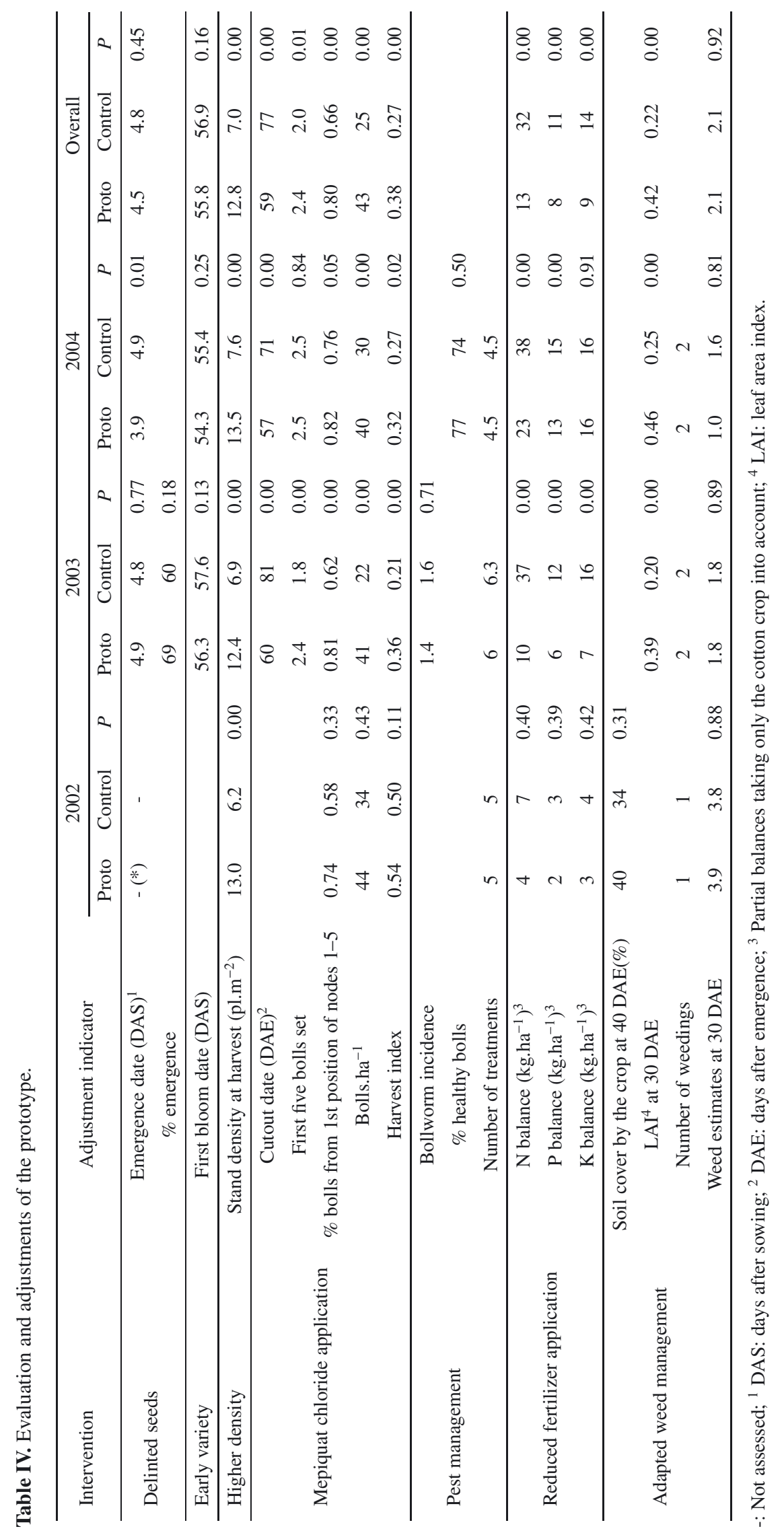



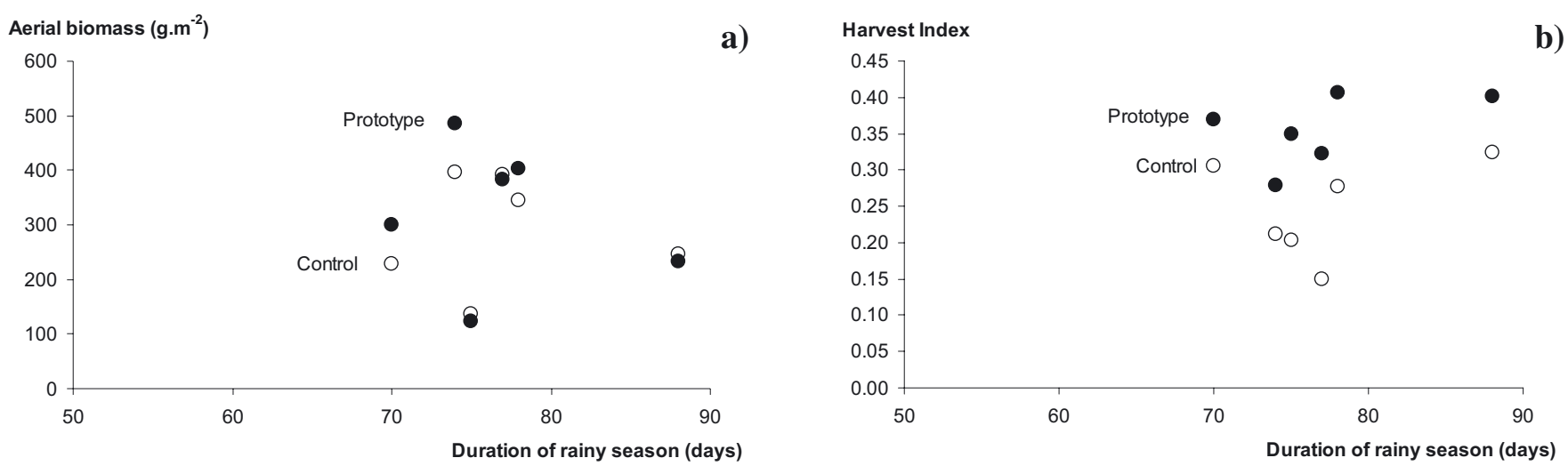

Figure 2. Aerial biomass at harvest (a) and harvest index of the prototype (b), compared with the control, as influenced by the duration of the rainy season available for the crop. Harvest index is the ratio between the seed-cotton dry weight and the total aerial biomass dry weight at harvest (including seed-cotton).

did not show any difference. In 2003 and 2004, we measured leaf area index at 30 days after emergence. Leaf area index was significantly higher in the prototype, as compared with the control. Nevertheless, it was not possible to find any significant effect of this quicker canopy closure on weeds when comparing the control and prototype.

The set of adjustment indicators was derived using the conceptual model presented in Figure 1. This formalization was a way to organize accumulated knowledge on the effects of technical interventions involved in producing the prototype, to explain the rationale underlying the intervention, and assess the consistency of each modification of the crop management system. It also helped in selecting the minimum set of indicators required to assess the benefits of each modification separately, as far as possible. Some interventions, mainly those introduced to group flower production within a shorter window, are not easy to separate, e.g. higher stand density and mepiquat chloride application. Although separated in the conceptual framework, the variety probably interacts with these interventions, as a short cycle variety also has limited vegetative growth.

Although the expertise was also important for deriving the proper indicator for each intervention, the adjustment indicators had to be adapted as they showed some deficiencies, presented in the text. Obviously, for another set of constraints, other technical interventions have to be implemented and the set of indicators may have to be modified.

The adjustment of the prototype relative to the theoretical prototype designed in step 2, as described in Table III, was rather limited. This limited adjustment may indicate that the theoretical prototype (Lançon et al., 2007) was good enough to require little tuning. Nevertheless, we feel that this limited adjustment was probably also linked to the fact that it was done by agronomists only, those who managed the trials. No scientists of other disciplines participated in these long trials and no other stakeholders were explicitly invited. This aspect could be changed in the future by introducing farmers earlier in the process. They were involved in the field tests and prototype adaptations only in 2005 (Turini, 2005), as defined in step 4 of the method proposed by Lançon et al., 2007. Earlier farmer involvement, i.e. in step 3, was not encouraged by the researchers, who preferred to independently test the new systems as there was a risk of failure or poor performance. This was probably a mistake, and farmer involvement in steps 2 and 3 should be considered.

Further refinements of the prototype are possible. For example, shortening of the window for boll protection against insects should lead to a lower number of insecticide sprays, probably without boll loss, and better economic performance. The prototype could also include more decision rules so as to tailor technical interventions to the actual status of the biophysical system (Barrabé et al., 2007). A decision rule on boll protection against bollworms was implemented in 2006 on 13000 ha under CDMT supervision. The first insecticide application was systematic, but further applications were decided according to a threshold based on bollworm counts. The second decision rule, which is not yet implemented in Mali, allows cost-effective application of mepiquat chloride (Barrabé et al., 2007) on the basis of simple indicators of the crop growth status.

\subsection{Assessment of the prototype}

The indicators presented in Table I were used to assess the prototype performances (Tab. V). The prototype succeeded in producing higher cotton seed and fiber yields, and higher income. The workload was increased, particularly for the time needed for sowing and thinning. Farmers in Mali thin cotton crops by hand, whereas most of them sow with oxen-draught sowing machines. All operations in our experiments were carried out manually. The workload increase for sowing measured in the research station may therefore not apply to on-farm conditions, whereas the increase related to thinning should apply. Work needed for harvesting was not modified by the prototype, when calculated per $\mathrm{kg}$ of harvested seed cotton. When applying the percentage of workload increase measured in the trial to the actual workload in on-farm conditions, we calculated an increase of $21 \%$ in the total workload of the prototype compared with the control. If cotton is machine-sown, then 
Table V. Assessment of the prototype for the main indicators presented in Table I (FCFA: Francs de la communauté française d'Afrique (West African currency). 1 Euro is 656 FCFA.

\begin{tabular}{|c|c|c|c|c|c|c|}
\hline Criterion & Indicator & & Proto & Control & $P$ & Assessment \\
\hline \multirow{4}{*}{ Yield } & \multirow{4}{*}{$\begin{array}{l}\text { Seed-cotton yield } \\
\qquad\left(\mathrm{kg} \cdot \mathrm{ha}^{-1}\right)\end{array}$} & 2002 & 935 & 805 & 0.48 & \multirow{4}{*}{$\begin{array}{l}\text { Highly significant difference, overall, } \\
\quad+48 \% \text {. In 2002, +13\%, increased } \\
\text { significantly in } 2003 \text { and } 2004(+73 \%)\end{array}$} \\
\hline & & 2003 & 659 & 357 & 0.00 & \\
\hline & & 2004 & 1100 & 668 & 0.00 & \\
\hline & & Overall & 852 & 536 & 0.00 & \\
\hline \multirow{3}{*}{ Workload } & Man-days.ha $^{-1}$ & Sowing & 16.3 & 5.3 & 0.00 & Sowing and thinning increased \\
\hline & per intervention & Thinning & 8.4 & 1.9 & 0.01 & sharply. First weeding time \\
\hline & (if done by hand) & Weeding & 13.5 & 9.3 & 0.00 & also increased \\
\hline \multirow{4}{*}{ Income } & \multirow{4}{*}{$\begin{array}{l}\text { Gross margin after } \\
\text { inputs paid (FCFA) }\end{array}$} & 2002 & 122950 & 100700 & 0.49 & \multirow{4}{*}{$\begin{array}{l}\text { For these late sowing dates, this } \\
\text { prototype always increased the } \\
\text { income. Nevertheless, variability } \\
\text { was relatively high, as it depended } \\
\text { mainly on yields }\end{array}$} \\
\hline & & 2003 & 56273 & -33053 & 0.00 & \\
\hline & & 2004 & 124985 & 41910 & 0.00 & \\
\hline & & Overall & 90290 & 14227 & 0.00 & \\
\hline Labor productivity & Gross margin / & $\begin{array}{c}\text { Overall } \\
\text { man-days } \\
\text { (FCFA/man-day) }\end{array}$ & 846 & 153 & 0.00 & $\begin{array}{l}\text { Although the workload increased, the } \\
\text { labor productivity also increased } \\
\text { with the prototype }\end{array}$ \\
\hline \multirow{4}{*}{ Quality } & Ginning outturn $(\%)$ & Overall & 40.4 & 44.6 & 0.02 & Decreased significantly \\
\hline & \multirow[t]{3}{*}{ Fiber quality } & Mean Length (mm) & 25.0 & 25.8 & 0.10 & \multirow{3}{*}{$\begin{array}{l}\text { Prototype did not negatively affect } \\
\text { the quality (check only in 2002) }\end{array}$} \\
\hline & & Strength (g/tex) & 33.3 & 31.5 & 0.26 & \\
\hline & & Micronaire & 3 & 3.2 & 0.24 & \\
\hline $\mathrm{N}$ pollution of aquifers & Partial N balance $(\mathrm{kg} \mathrm{N} / \mathrm{ha})$ & Overall & 4 & 23 & 0.00 & 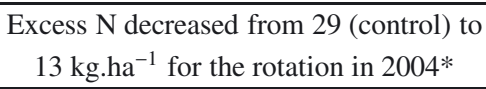 \\
\hline $\begin{array}{l}\text { Environmental pollution } \\
\text { by pesticides }\end{array}$ & $\begin{array}{c}\text { Number of pesticide } \\
\text { applications }\end{array}$ & Overall & 7.1 & 6.3 & 0.00 & Maintained at the level of the control \\
\hline Risk & $\begin{array}{l}\text { Cash investment } \\
\text { in the crop (FCFA) }\end{array}$ & Overall & 80100 & 82900 & 0.16 & $\begin{array}{l}\text { Similar to control, but increased } \\
\text { from } 2002 \text { to } 2004 \text {, mainly } \\
\text { due to higher fertilizer application } \\
\text { to maintain a positive } \mathrm{N} \text { balance } \\
\text { for a typical rotation }\end{array}$ \\
\hline
\end{tabular}

* Partial balance is calculated assuming a $100 \%$ uptake of fertilizers.

the calculated overall workload increase would be $15 \%$, taking into account the increase in sowing time due to the higher number of rows to sow. Although modest, this workload increase mostly occurs during the heavy workload period on farms when sowing, thinning and first weeding are carried out.

As the yield increased and costs decreased or stayed similar in the prototype, gross margin also increased significantly for the prototype (Fig. 3). Labor productivity was calculated, assuming application of the prototype to on-farm conditions using a sowing machine. For 2003, gross margin and labor productivity were negative for the control, due to the very low yields at one station. Although gross margin was highly variable across years, the prototype consistently gave better results than the control.

The prototype performed poorly on ginning outturn, whereas there was no difference with respect to fiber quality. Ginning outturn is mainly driven by the cotton variety, and substantial breeding efforts have focused on this parameter in West Africa, perhaps more than in any other place in the world. The West-African varieties used in the control therefore had higher ginning outturn than the US variety used in the proto- type. When a Malian variety was tested with the management proposed in the prototype, the ginning outturn did not differ from the control (data not shown). This point is important, as seed-cotton is traditionally bought to farmers, at a price that does not depend on the ginning outturn. Therefore, the introduction of a new variety with lower ginning outturn may be not compatible with the current cotton supply chain, or will need extra -and difficult- negotiation on the cotton price.

A new type of cotton variety is clearly needed to improve the prototype performance, i.e. a variety that resembles DES119 but with the ginning outturn of the Malian variety. This would increase the prototype performance for farmers, while keeping the fiber quality at the level of the control cotton management system. This quality is essential for the country to maintain its position in the world cotton market. Such work has already been initiated in Benin (Sekloka et al., 2007).

The partial $\mathrm{N}$ balance was decreased in the prototype, mainly due to higher exportations related to higher yields. Fertilization rates are low in rural areas and $\mathrm{N}$ excess is not usually considered to be an environmental threat. On the contrary, pesticide pollution is a current concern. In this case, the prototype 

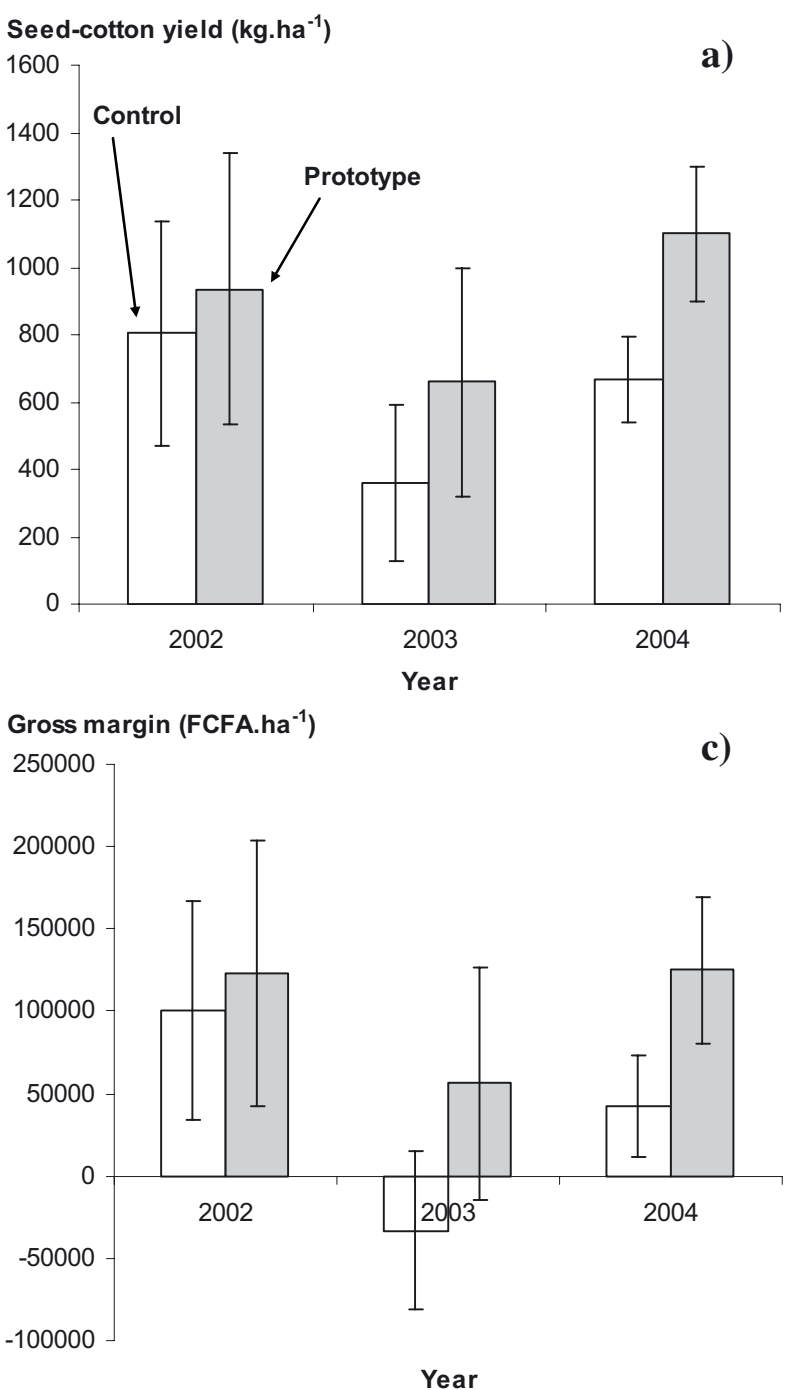

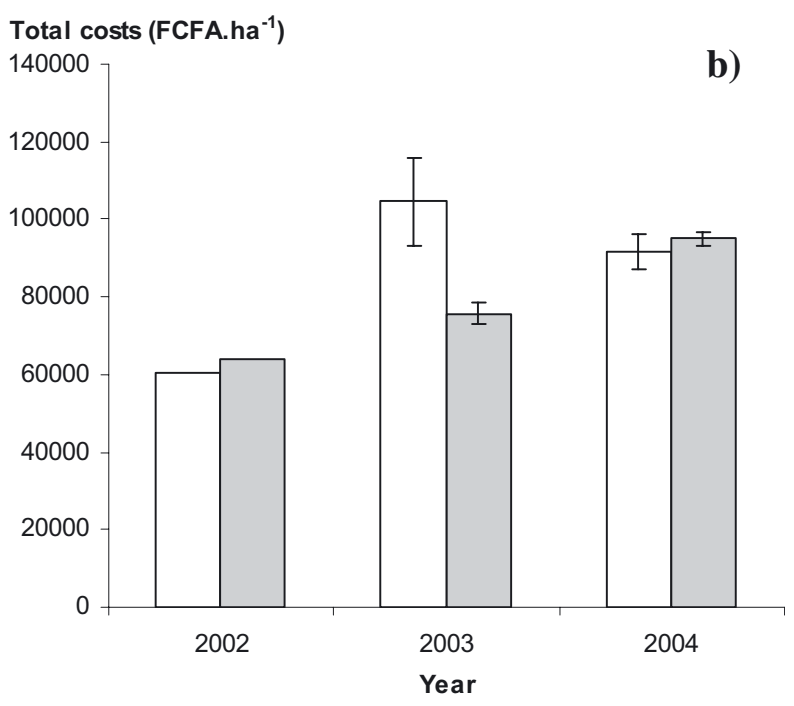

Labor productivity (FCFA per day)

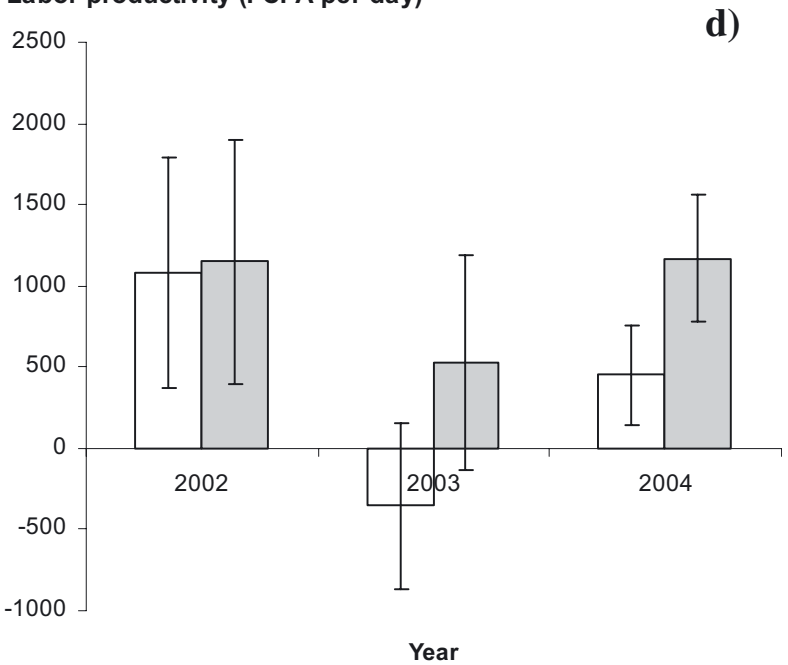

Figure 3. Variations in the average performances of the experimental prototype (late sowing) for the different years: (a) seed-cotton yields; (b) total costs; (c) gross margin; and (d) labor productivity. The different years also correspond with different soil and climate conditions. Error bars represent one standard deviation on each side. They were calculated on the basis of the yield of each elemental plot (a, c and d), and on the basis of the average in each experimental location (b).As the experiment was implemented in only one location in 2002 , no standard error could be derived for this year in $b$.

stayed at the same level as the control. The only indicator measured in the social domain, i.e. the risk taken, was similar in the prototype and control (Tab. V).

The set of indicators used to assess the sustainability of the prototype and its suitability to the target set of constraints concerns different domains. The tradeoffs between domains or criteria were not explicitly considered, in the way that it was done in other studies, particularly on a farm scale (van Keulen, 2007). The main discussion here concerned the increased labor needed to implement this prototype. This increase is considered warranted, as labor productivity also increased, when cotton was mechanically sown. Labor is needed on the farm scale to sow and weed other crops at the beginning of the rainy season, particularly pearl millet, maize and sorghum. As these grain crops are very important for family food security, the increased labor demand of the prototype may not be acceptable for farmers, even though labor productivity increases. The weighing of the assessment criteria, e.g. labor needs and labor productivity here, must therefore be discussed with farmers.

The prototype results show high fluctuations across sites and years (Fig. 3). These fluctuations are obviously at least partly linked with the rainfall patterns in the rainy season and with the soil fertility of the site. The understanding of the origins of these fluctuations would help in comparing the risks associated with the prototype. Crop simulation models are widely used to test the effects of climate variability on cropping system performances (Scopel et al., 2004). A preliminary check was done by Barrabé (2004) with a water balance model only, i.e. not connected with biomass or cotton production, for late-sown cotton in the Koutiala region in Mali. 
The results indicated that the shortening of the fruiting period avoided water stress towards the end of the fruiting period during some years, and that it did not increase water stress probability or effects at the beginning of the fruiting period. The use of OZCOT, a cotton crop simulation model integrated into the APSIM model (Hearn, 1994), may improve the accuracy and confidence of these predictions. This model is already being calibrated in Mali in order to assess these prototypes under different climatic conditions.

The combined use of simulation models and prototyping to efficiently produce and test new crop management systems is attractive. Models are based on usually well-established and organized academic knowledge. They have been used to test a very high number of crop management systems at low cost (for example, Dogliotti et al., 2003, 2004). Prototyping is useful to produce crop management systems with marked changes with respect to current practices, to organize expert knowledge that is not sufficiently formalized to be used in simulation models, but which is very useful as it closely reflects the actual situation in the field. The prototyping process is also easier to link with farmers' experience as the knowledge is of the same nature. Attempts to explore the combined use of these methods have so far been theoretical elaborations rather than organized actions in the field (Sterk et al., 2007), although very recent research showed the usefulness and applicability of this combination (Blazy et al., 2009a).

The method used here for designing a novel crop management system allowed one to define and adjust a prototype that outstrips the control in many aspects related to sustainability. The method relies on an agronomic evaluation for adjustment of the prototype, combined with an overall assessment of its performance along different sustainability pillars. However, the prototype and the method can be improved to ensure higher usefulness of this prototype for farmers and for the sector. The method used to design the first proposal for the prototype relies on the addition of practices that concur with the shortening of the crop cycle. The posterior adjustment process allows selecting the practices that are effective in this shortening. Nevertheless, we have no way to ensure that the cycle is shortened to the optimal length. Such iterative work, which depends on the weather of a particular year, would require the combination of this approach with the use of a model.

This work was performed on a field scale, and the overall assessment showed that it increases the workload at the beginning of the crop cycle. The possibility of the farmers meeting this extra work demand will probably depend on the farm characteristics, and will need tradeoffs to be decided. An adaptation of the prototyping method on a field scale to different farm characteristics has been proposed recently (Blazy et al., 2009b), and may be usefully applied to overcome such limitation.

Farmers' interactions could also have ensured a better adaptation of the prototype to local and particular constraints, thus improving its possible adoption. They were not favored during the trial process. We could have done otherwise, but the opportune inclusion of farmers in this time-consuming process is not an easy task, as was also observed by other research teams (Blazy et al., 2009b).

\section{CONCLUSION}

A cotton cropping system prototype for limited rainfall conditions was designed, tested, assessed and adjusted during a 3 -year process. The prototype aims at shortening the cotton cycle and is particularly suited for late sowing, or for regions with low rainfall. A conceptual model was developed which describes modifications in technical interventions that could be made to meet this objective and their coherence. A set of indicators is derived to adjust the interventions, in an iterative process.

The prototype was then tested and adjusted in six trials between 2002 and 2004 with late sowing, and four situations with low rainfall. The prototype produces higher seed-cotton yields ( $+44 \%$ on average) and much higher income. Shortening of the cycle was achieved not by earlier flowering, but rather by a shorter ( -15 days on average) and more intense flowering period. The combination of a much higher stand density and application of mepiquat chloride produced a much higher number of bolls per hectare $(+69 \%)$.

The results showed good overall performance of the prototype, indicating that the process was effective for designing improved crop management systems in a multi-criteria approach.

The methodology proposed here was useful for designing a new Crop Management System. It may be improved, particularly with respect to communication with farmers, which was not sufficiently organized and was too late in this example. The use of simulation models in this process may also increase the confidence in the stability of the results across soil types and years.

\section{REFERENCES}

Barrabé A. (2004) Mise en place d'une règle de décision pour l'application d'un régulateur de croissance, le chlorure de mépiquat, sur culture cotonnière au Mali, M.Sc. thesis, ENSAM, Montpellier, $38 \mathrm{p}$.

Barrabé A., Rapidel B., Sissoko F., Traoré B.S., Wery J. (2007) Elaboration and test of a decision rule for the application of mepiquat chloride on cotton in Mali, Eur. J. Agron. 27, 197-204.

Blazy J.-M., Dorel M., Salmon F., Ozier-Lafontaine H., Wery J., Tixier P. (2009a) Model-based assessment of technological innovation in banana cropping systems contextualized by farm types in Guadeloupe, Eur. J. Agron., in press.

Blazy J.-M., Ozier-Lafontaine H., Doré T., Thomas A., Wery J. (2009b) A methodological framework for taking into account the diversity of farms in the prototyping of sustainable crop management systems. Application to banana-based systems in Guadeloupe, Agric. Syst., in press.

Bourland F.M., Benson N.R., Vories E.D., Tugwell N.P., Danforth D.M. (2001) Measuring maturity of cotton using nodes above white flower, J. Cotton Sci. 5, 1-8.

Braud M. (1987) La fertilisation d'un système de culture dans les zones cotonnières soudano- sahéliennes, Coton Fibres Trop. 42, 7-35.

Buxton D.R., Patterson L.L., Briggs R.E. (1979) Fruiting pattern in narrow-row cotton, Crop Sci. 19, 17-22.

CMDT (2001) Note sur l'utilisation des engrais chimiques en zone CMDT, Campagne 2001/2002, CMDT, DTDR, LRD, Bamako, Mali. 
Deguine J.P., Ferron P., Russell D. (2008) Sustainable pest management for cotton production. A review, Agron. Sustain. Dev. 28, 113-137.

Devèze J.C., Halley des Fontaines D. (2005) Le devenir des agricultures cotonnières; Cas du Mali, AFD, Paris.

Dogliotti S., Rossing, W.A.H., van Ittersum M.K. (2003) ROTAT, a tool for systematically generating crop rotations, Eur. J. Agron. 19, 239-250.

Dogliotti S., Rossing W.A.H., van Ittersum M.K. (2004) Systematic design and evaluation of crop rotations enhancing soil conservation, soil fertility and farm income: a case study for vegetable farms in South Uruguay, Agric. Syst. 80, 277-302.

Fok M.A.C., Djouara H., Koné M., Ballo D. (1999) Diversité des pratiques paysannes en zones cotonnières du Mali ; portée et limites des gestions d'itinéraires techniques observés, in: Deguine J.-P., Fok M., Gaborel C. (Eds.), Rôle et place de la recherche pour le développement des filières cotonnières en évolution en Afrique, CIRAD, Montpellier, p. 238.

Hearn A.B. (1994) OZCOT: a simulation model for Cotton crop management, Agric. Syst. 44, 257-299.

IER/CMDT/OHVN (1998) Mémoire de réunion de concertation sur la baisse de rendement de la variété NTA 88-6 au cours de la campagne 97/98, Institut d'Économie Rurale, N’Tarla, Mali.

Issa M.Y. (2004) Contribution à l'étude de l'impact de l'utilisation des pesticides sur la faune terrestre et aquatique : cas des grands mammifères et de quelques espèces de poissons dans les réserves de biosphère de la Pendjari et du W. Msc. Thesis, Université d'Abomey-Calavi, Cotonou, 109 p.

Jones M.A., Wells R. (1997) Dry matter allocation and fruiting patterns of cotton grown at two divergent plant populations, Crop Sci. 37, 797-802.

Lançon J., Wery J., Rapidel B., Angokaye M., Gérardeaux E., Gaborel C., Ballo D., Fadegnon B. (2007) An improved methodology for integrated crop management systems, Agron. Sustain. Dev. 27, $101-110$

Marnotte P. (1984) Influence des facteurs agroécologiques sur le développement des mauvaises herbes en climat tropical humide, $7^{\mathrm{e}}$ Coll. Int. sur Biol., Ecol. et Syst. des Mauvaises Herbes, Paris, pp. 183-190.
Ranney C.D., Cauquil J. (1968) Méthodes employées aux États-Unis pour établir et conserver au champ une bonne densité de levée, Coton Fibres Trop. 23, 191-200.

Rapidel B., Defèche C., Traoré B., Lançon J., Wery J. (2006) In field development of a conceptual model for crop functioning and management: a case study on Cotton in Southern Mali, Eur. J. Agron. 24, 304-315.

Scopel E., Da Silva F.A.M., Corbeels M., Affholder F., Maraux F. (2004) Modelling crop residue mulching effects on water use and production of maize under semi-arid and humid tropical conditions, Agronomie 24, 383-395.

Sekloka E., Lançon J., Gozé E., Hau B., Lewicki S., Thomas G. (2007) Breeding new cotton varieties to fit the diversity of cropping conditions in Africa-Effect of plant architecture, earliness and effective flowering time on late-planted cotton productivity, Exp. Agr. 44, 197-207.

SSE/CMDT (2002) Enquête spécifique sur les Coûts de Production du Coton, Analyse des résultats, CMDT, Service Suivi Évaluation, Bamako.

Sterk B., van Ittersum M.K., Leeuwis C., Wijnands F.G. (2007) Prototyping and farm system modelling-Partners on the road towards more sustainable farm systems? Eur. J. Agron. 26, 401-409.

Traoré B.S., Rapidel B., Sissoko F., Doucouré C.T. (2006) Évolution des techniques culturales en zone cotonnière du Mali entre 1994 et 2002, Cah. Econom. Rur. 2, 21-28.

Turini T. (2005) Adaptation en milieu paysan d'un prototype d'itinéraire technique. Cas de la culture cotonnière en condition de forte contrainte hydrique, M.Sc. thesis, ENSAM, Montpellier, 86 p.

van der Pol F. (1992) Soil mining, an unseen contributor to farm income in southern Mali, Royal Tropical Institute, Bulletin 325, Amsterdam.

van Keulen H. (2007) Quantitative analyses of natural resource management options at different scales, Agric. Syst. 94, 768-783.

Vereijken P. (1997) A methodical way of prototyping integrated and ecological arable farming systems (I/EAFS) in interaction with pilot farms, Eur. J. Agron. 7, 235-250.

Yehouessi M. (1984) Résultats de trois années d'expérimentation sur la désinfection des semences de cotonnier à la station de Bebedjia, Coton Fibres Trop. 39, 95-97. 